\section{Horse Mummification in Ancient Egypt}

MUMMIFICATION of sacred animals is a familiar practice in the annals of Ancient Egypt, especially in the later periods. A discovery of what is thought to be the earliest known example of the mummifieation of a horse has recently been made on the hill of Sheikh Abdel Kurneh, on the west bank of the Nile at Thebes, by an expedition of the Metropolitan Museum of New York under the field direction of Mr. Winlock. The expedition is carrying on $\mathbf{M r}$. Winlock's excavation interrupted in 1927, when he discovered the tomb of Sen-Mut, the architect of the famous temple of Queen Hat-shepsut at Deir elBahari. The work of the present season, it is stated in a dispatch from Cairo in The Times of April 6, has brought to light the intact tombs of Ra'mose and Hatnufer, the father and mother of Sen-Mut. In clearing the bottom of the ravine preparatory to opening the rock chamber, in which the burials were found, the body of a horse was uncovered in the limestone clip. It had been mummified and wrapped and enclosed in an enormous coffin. It is of the $x$ viiith dynasty and, therefore, probably the oldest horse burial found in Egypt up to the present. The rock chamber was crowded with funerary material, including jars and baskets containing linen, food, and in one instance a silver bowl and two small pitchers for mixing wine. Two jars are dated the seventh year of Tuthmosis III, while some of the linen and jar sealings bear titles of Hat-shepsut when she declared herself King of Egypt. On one side of the chamber were uninscribed rectangular coffins and on the other anthropoid coffins bearing inscriptions indicating that they contained the bodies of Ra'mose and Hatnufer. Neither had an official title.

\section{Messrs. Taylor, Taylor and Hobson, Ltd.}

THE fiftieth anniversary of the foundation of the firm of Messrs. Taylor, Taylor and Hobson, Ltd., manufacturing opticians and engineers, was celebrated on Monday, April 6, by a dinner given by the directors to all employees and a few guests. The brothers Mr. Thomas Smithies Taylor and Mr. William Taylor, F.R.S., were the founders of the business in 1886. The first lenses produced by the firm were known as Rapid Rectilinear lenses. These were followed by single achromatic 'View' lenses and wide angle lenses. Mr. William Taylor at this time devoted a great deal of attention to establishing the manufacture of lenses and lens parts on an interchangeable basis, and providing means of cutting screw threads accurately. The abruptly started thread was devised and patented, and he started the practice of measuring screw threads trigonometrically with a micrometer, and with little cylinders, or wires, put between the threads, and of measuring threading tools and the amount by which they were shortened from a theoretically perfect point, by means of a notched bar. The methods were gradually developed and led to the manufacture of the engraving machine which is now well-known as the 'Taylor-Hobson Engraver'. Mr. W. Taylor has served on many standardisation committees and was responsible for establishing the principle that in gauging screw threads, the 'go' gauge must include all the elements and the 'no-go' gauges deal with them separately, except that pitch and effective diameter must be gauged concurrently. The election of Mr. W. Taylor as a fellow of the Royal Society in 1934 was a mark of recognition by British men of science of his pioneer work in the application of mechanical engineering to the manufacture of optical instruments, and the improvements of photographic lenses.

\section{The Aberdeenshire Dee}

Rrver Flow Records, the private organisation directed by Capt. W. N. McClean, has just issued in brochure form (Parliament Mansions, London, S.W.l. 10s. 6d.) a complete account with diagrams of the observations and readings taken for the year 1935 in connexion with the survey of the River Dee (Aber. deenshire), comprising records of water-level, flow and rainfall. The diagrams, in four sheets, exhibit in coloured outline the monthly water-levels at Cairnton Gauge Post in 3-hourly averages, and the aggregate rainfall and run-off over a catchment area approximately of 528 square miles. The value of these monthly diagrams has been enhanced since their publication for 1934 by the inclusion of the maximum and minimum temperatures and wind at Balmoral and by the incidence of rainfall from the automatic rain gauge. Thus the occurrence of snow and the effect of temperature in increasing or dimin. ishing the flow become clear in winter and spring months. The effect of wind is not obvious, and it appears likely that certain changes in water-level, which, locally, are attributed to strong down-stream winds, may be due to temperature.

ONE aim of the records is the comparison of rainfall with run-off. Daily rainfall observations were taken from ten gauges widely distributed over the area, and acknowledgments are made of the assistance rendered by the Meteorological Office at Edinburgh, the British Rainfall Organization, the Royal Meteoro. logical Society and voluntary observers. The mean annual rainfall on the area of 528 square miles given by the British Rainfall Organization is $42 \mathrm{in.}$; the year 1935 provided $42 \cdot 7$ in. and $1934,48 \cdot 4$ in., deduced from daily observations at the ten gauges mentioned above, combined with the mean distri. bution of rainfall on the area. Assessed at the end of September in each year, when the ground satura. tion is generally low and therefore negligible, the residual loss was 8.34 in. in 1933 ; 11.48 in. in 1934 and 7.36 in. in 1935. The operations of River Flow Records are extremely valuable as an aid to a national inland water survey, and the report suggests the formation of a committee of river interests, under the independent patronage of the county, to carry the Dee survey to fruition, but "the final picture would be incomplete" without the central supervision and financial support of the Government.

\section{Protection of Wild Life in Africa}

THE Convention for the Protection of the Fauna and Flora of Africa, signed on behalf of nine Govern. ments in London on November 8, 1933, became 
effective on January 14, 1936. The ratified articles have therefore come into force in all the African territories of Great Britain, Belgium, Egypt, the Anglo-Egyptian Sudan and the Union of South Africa (Science Service, Washington, D.C.). As a result, gorilla, okapi, white rhinoceros, pigmy hippopotamus and eighteen other rare wild animals, together with the unique plant of the Kalahari Desert, Welwitschia, are now absolutely protected. Protection almost as complete is afforded to a series of animals in List A, which may not be killed for ordinary purposes at all, either by natives or whites, but may be taken in strictly limited numbers, with Government permission, for important scientific purposes. There are included such African elephants as possess tusks less than ten pounds in weight. If the tusks be heavier than ten pounds, the elephants fall into Class $B$, where they are partnered by black rhinoceros, the two species of giraffe, the wild ostrich and several kinds of egrets and hornbills. Class B animals may be hunted only by special licence, whereby the area, time and extent of the hunting is strictly limited and defined.

\section{British Empire Naturalists' Association}

AT the annual general meeting of the British Empire Naturalists' Association to take place in the Artworkers' Guild Hall, London, on April 29, under the chairmanship of Mr. Richard Morse, the lecturer will be Mr. D. Seth-Smith, curator of birds at the London Zoological Gardens. The Council of the B.E.N.A. has recently drawn up a resolution protesting against the choice by the Air Ministry of a section of the Northumberland coast near the Farnes, frequented by many uncommon birds and including the only English breeding station of the eider duck and the only East England breeding station of the grey seal, for a future bombing station. A new local branch for Shropshire has recently been formed by the Association, and has already begun activities. It has been decided to hold the annual B.E.N.A. allnight ramble and dawn bird song record in Surrey on the night of Saturday-Sunday, May 23-24, the organisation of this being carried out by Mr. W. J. Finnigan, who has cared for the previous all-night meetings. The B.E.N.A. herbarium, for long at Bexhill, has now been transferred to the South London Botanical Institute, 323 Norwood Road, London, S.E.24, where it may be inspected daily from 2 until 9 p.m. except on Thursdays, Sundays and days of outings of the Institute.

\section{Electric Developments in British Ships}

DURING the last three years, the shipowning and shipbuilding industries have been seriously depressed. It is satisfactory therefore to learn from a paper by Colonel A. P. Pyne (J. Inst. Elec. Eng., February) that steady progress has been made in the applications of electricity in British ships. The popularity of short cruises in large luxury liners has favoured develop. ment. The problem of ventilation has attracted attention. It is now recognised that the stirring up of air by means of fans, or even the delivery of warmed or cooled air to given points by means of ducts, does not suffice. Air conditioning now takes into consideration the problems of the draughtless delivery of purified air and the extraction of vitiated air in the proper proportions. The incoming air must have the right temperature and the correct humidity to suit the climatic conditions of the moment. The air conditioning plant now changes the supply to warmed or cooled air automatically as required. The electric heating of public rooms and cabins is becoming universal. The heaters adopted are generally of the convector type, made more cheerful by luminous effects. The depression of the industry has prevented electric marine propulsion from making much progress. Two large motorships, the Stirling Castle and the Athlone Castle, each having a tonnage of 25,500 and auxiliary generators of 3,500 kilowatts for lighting and power, are at present being built. The Queen Mary, having a tonnage of 73,000 , has auxiliary generators of 9,100 kilowatts capacity. The steam turbo-electric Normandie built in France last year has a tonnage of 75,000 and auxiliary generators for lighting and power of 13,200 kilowatts.

\section{New Telephoto Systems in the United States}

THERE are various methods now in use in different countries for transmitting photographs, printed matter and line drawings by means of telegraph or telephone wires or by radio. In certain respects the circuits must meet more stringent requirements than those used by speech or m!nsic. The sending apparatus scans the picture in closely spaced lines and converts the light and dark portions into electric currents proportional in strength to the light and shade of the picture. The transmission along the line causes a weakening of the current, but this is got over by amplification at the receiver. In a circuit for tele. photography the successive portions of the signal are spread out side by side so that all are seen by the eye at the same time. In telephoning, the ear hears them one after the other and any slight blurring is scarcely noticed. Any little irregularity in the time sequence of the signals is at once seen in the telephotograph and remains as a permanent record. In the Bell Laboratories Record of February, P. Mertz describes how this defect can be remedied by equalising the 'time delay' of the signals (which is done in the new Western Electric telephotograph system). For good pictures this time delay of the various rays in the transmission band must not exceed the twothousandth purt of a second. Photographs are given showing the great improvement produced by using this device on the transmission line. It is also shown how 'random noise', telegraph interference, highfrequency noise and 'echo' distort the photograph. The first of the new telephoto systems to be installed connects Miami, Washington, New York, Boston, Chicago, San Francisco, etc., and includes 7,400 miles of main circuit. In a single connexion between sender and receiver, there may be as much as 3,500 miles of cable and 2,500 miles of open wire. 